\title{
Family Violence and its Impact on Children's Mental Health During COVID-19 Pandemic
}

\author{
Prof. Zinab, M. Shokair ${ }^{1}$, Prof. Eid G. Abo Hamza ${ }^{2}$ \\ ${ }^{1}$ Faculty of Education, Department of Mental Health, Tanta University, Egypt \\ ${ }^{2}$ College of Graduate Studies, Arabian Gulf University, Bahrain
}

\begin{abstract}
This research aims to identify the types and prevalence rates of family violence against children during the COVID-19 pandemic lockdown. It also aims to identify the mental health problems those child victims of family violence develop, and the differences between children who experience high and low family violence rates. The research was conducted on a sample of $(n=160)$ child victims of family violence in primary schools. The researchers applied an assessment of family violence of their design, and the results were very high. Then they applied an assessment of mental health problems they designed and which included 8 problems which all sample members suffered from. The scale was based on an open question, and the results showed that the violence types with high rates (compared to average and low rates) were ranked as follows: threat with violence, moral violence, social violence, economic violence, and lastly physical violence. The results also showed increase in the 8 mental health problems high rate (compared to the average and low rates), and the problems were as follows: lying, destructivity, impulsivity, aggressiveness, fear, night terror attacks, self-harm and finally self-hate. Furthermore, this research addresses the high rates of family violence's negative impact (compared to the low rate) on the increase of mental health problems. F test result was $(40.11, p$ $\leq$ 0.05). At the end, the researchers concluded several practical recommendations and implications.
\end{abstract}

Keywords: Family Violence, Mental Health Problems, COVID-19 Pandemic, Children.

\section{Introduction}

Family violence alludes to compromising or other rough conduct inside families that may be physical, sexual, mental, or financial, and can incorporate youngster misuse and personal accomplice viciousness [1]. Family brutality during pandemics is related with a scope of variables including financial pressure, disaster-related flimsiness, expanded presentation to exploitative connections, and diminished choices for help. Because of the social detachment estimates actualized over the globe. Family brutality during pandemics is related with a scope of variables including financial pressure, disaster-related flimsiness, expanded presentation to exploitative connections, and diminished choices for help (Peterman et al. 2020). Because of the social 
detachment estimates actualized over the globe [2].

Social quarantine exacter-bates individual and gather weaknesses while limiting open and recognizable help alternatives [3]. In numerous nations, including Egypt, we have observed an expansion sought after for domestic violence administrations and reports of expanded danger for children not going to schools, a pattern similar to past scenes of social disconnection associated with scourges and pandemics [4].

As the whole world is facing the rapid spread of COVID-19 and the high rates of death it is causing, the international community was appealed to support those infected. The virus is threatening the lives of many people, therefore, many international organizations [5] called upon the international community to protect the rights of those infected, and to provide them with health and mental care services needed. This example is rehashed globally. Reports of home grown maltreatment and family brutality have expanded far and wide since social disconnection and isolate measures came into power. As of late, narrative proof from the United States, China, Brazil, and Australia shows increments in close accomplice, women, and youngsters' viciousness because of seclusion and quarantine. China, the first nation to force mass isolate in the Wuhan area, saw announced homegrown maltreatment episodes rise triple in February 2020 contrasted with the earlier year[6].

Expanding reports of aggressive behavior at home during the Covid-19 pandemic

It has been reported in France a 32\% - 36\% increase in domestic abuse com-plaints following the implementation of self-isolation and quarantine measures [7]. UK has likewise observed worries about increment in family savagery, there have been reports of murder related with family savagery in a few nations [8]. The National Domestic Abuse Hotline in the UK saw a $25 \%$ expansion in calls since stay-athome measures were actualized, recording at any rate eight family savagery related passing [9]. As isolate measures reached out to the United States, singular states announced comparable increments in homegrown maltreatment episodes extending from $21 \%$ to $35 \%$, Reports of expanding paces of aggressive behavior at home are starting to surface everywhere. In China, aggressive behavior at home is accounted for to have significantly increased during their safe house set up command. Moreover, Brazil gauges aggressive behavior at home reports have bounced 40-50 \% [10]. and Italy has additionally demonstrated reports of abusive behavior at home are on the ascent. In Spain, reports have surfaced of an awful abusive behavior at home related murder - a pattern that is tragically prone to proceed the world over as stress keeps on building and sanctuary set up measures stretch out into what's to come. The developing worldwide pattern of expanding reports of abusive behavior at home cases is probably going to proceed all through the pandemic and may just speak to a "hint of something larger" the same number of casualties actually wind up caught with the culprit and unfit to report the maltreatment [11],

Lockdowns were taken as a measure against the pandemic. Families' presence in one place all day, every day caused increase in violence rates in the majority of Egyptian families, Family violence occurs in both poor and rich families, and it include violence against children perpetrated by parents, violence between siblings, violence against wives, etc. violence against children happens in many different types, but family violence is the most dangerous one. It is often the result of the parents' psychosocial conditions. Family violence doesn't only cause increase of crime rates rise only, but it also shapes the child's personality. Family violence impacts all aspects of the child's life, as it negatively impacts their mental health, and leads to emotional and behavioral disorders and psychological insecurity[12].

Family violence is irrational, behavioral responses perpetrated against children by one of their family members -father, mother, brother, sister, or the one responsible -or all of them. Family violence varies in types and it could include intense hatred, beating, insulting, offending or threatening. Family violence is usually the result of low understanding -or complete ignorance- of parenting methods [13] 
In the United States, offices from the nation over are likewise detailing an expansion in abusive behavior at home. Notwithstanding danger of physical mischief, casualties are likewise at incredible danger of enthusiastic damage and misuse. U.S. reports have surfaced of abusive behavior at home culprits utilizing Covid-19 as a weapon against their casualties, prohibiting hand washing trying to expand the casualty's dread of getting the infection and taking steps to restrict clinical treatment if the casualty gets the infection [14].

Furthermore, considers show the expanded paces of abusive behavior at home revealed after a catastrophic event frequently reach out for a while after the disastrous occasion happens [15]. Indeed, an examination taking a gander at the fallout of catastrophic events in the United States and Canada discovered abusive behavior at home casualty administration demands expanded for a whole year following the occasion , Family savagery casualty serving experts must know about the high probability of increments in exploitation rates and reports both during and long after the Covid-19 pandemic[16].

Family violence has very negative impacts on children. They are likely to develop problem solving approaches that include violent behaviors, which might eventually lead to future failure. Abused people tend to hold grudge, hatred and fear. And to express these emotions and the stress violence causes, they tend to be stubborn whenever they are given the chance, challenging and refusing others' opinions no matter how objective they are. This research addresses the behavioral, emotional and social disorders of children exposed to family violence, as a result to their childhood's bad mental health conditions. Child victims of family violence's mental health problems take the form of many behavioral and social problems. The focus is the 8 following problems:

1- Aggression: all active and passive behaviors, whether direct or indirect that cause physical and mental harm to anyone, including the doer themselves (Allen, Anderson \& Bushman, 2018).
2- Impulsivity: giving quick responses to the surrounding events without giving any thought to the response's results. [17]

3- Lying: it is a learned behavior where the child intentionally delivers false news or information, whether verbally or by taking some action, even though they realize (and are completely aware) that that's not the truth. The child might lie because they feel jealous, crave attention, fear punishment, want to revenge from others or cause them harm, suffer from serious psychological disorders or simply because they're not sure of truth.

4- Destruction: this includes all behaviors the child does with intent to destruct and damage things around them like furniture, toys and tools, whether they're aware of the result or not. [18]

5- Self-punishment: all odd and weird behaviors the person punishes themselves with. It is usually a rebellious expression of anger where the person deprives themselves from all privileges, and by torturing and hurting themselves or parts of their bodies. These behaviors also include self-devaluing and selfdestructive thoughts.

6- Hatred: the person tends to enjoy this feeling, whether it's self-hate, hate of others, hate of surroundings, such as subjects and incidences. This feeling is usually accompanied with destructive thoughts and behaviors like violence, self-harm, self-isolation, and harming those who caused this feeling. Hatred is the result of subconscious feelings of inadequacy, jealousy and grudge. Or conscious thoughts such as mistaken beliefs and knowledge. Or ulterior social and environmental motives such as pressure, crisis, disasters, injustice and persecution[19]

7- Sleep terror disorders: symptoms include loud voices, hyperkinetic syndrome and high activity levels in the autonomic system. In the first third of 
night, the person often wakes screaming, sits or stands up and runs to the door trying to escape. They wake up partially unconscious, and they hardly response when others try to calm them down. When they wake up in the morning they usually don't remember the sleep terror they had.

8- Phobia: it arises from normal, familiar subjects that aren't scary, and varies from fear to horror. The response is usually accompanied with stress and dangerous impulsive behaviors [20].

Extensive review of the integrative investigation of brutality violence keeps on being one of the direst worldwide general medical issues that contemporary society faces. Domestic violence against youngsters and teenagers was a danger factor for the improvement of mental issues [21]. Suicides and manslaughters are expanding at a disturbing rate, especially in more youthful age gatherings and lower-pay nations. Truly, the investigation of viciousness has been divided across different fields of study with minimal cross-disciplinary cooperation, subsequently making a barrier to deciphering the fundamental cycles that offer ascent to savagery and blocking endeavors in examination and counteraction.

Many studies were inducted on the relationship between emotional and behavioral problems and the mental health of children and teenagers. These studies showed high rates of impulsivity, aggressiveness and destructivity for child victims of violence (compared to normal children) in primary schools [22].

Hboula's study also outlined the relationship between mental health problems and parenting approaches, as well as the types of violence children and youth are exposed to, such as family violence, school violence and violence against wives. The results of these studies show the impact of negative family atmospheres on children's emotional and behavioral problems. They also outline the relationship between harsh parenting and children's behavioral problems, like aggressiveness, lying and stubbornness[23]. As the pandemic is developing through stages, this paper assesses the effect these stages may have on mental strength of youngsters and youths and the arrangement of mental administrations. This paper features some key difficulties and worries for treatment and examination on youngster. In addition, this paper will offer a few suggestions that can be embraced right away. The scope of these studies is limited to few mental health problems only, which demands more studies to be conducted on the subject, especially with the current increase of family violence in all communities. This research is conducted with a scope of 8 mental health problems that are results of intense family violence [24].

The research's problem is to answer the following questions:

1- What is the prevalence rate of high family violence levels? And how does family violence impact primary school students?

2- What are the most important and common mental health problems child victims of family violence -primary school students- suffer from? What is their prevalence rate?

3- Do family violence levels (high - low) impact the level of mental health problems?

\section{Methodology}

The descriptive method was used on a gender balanced sample of (160) elementary students of 5 th and 6th grade. All sample members are victims of high family violence levels, according to the family violence and mental health problems scales the researchers designed. The researchers collected data via snowballing method (i.e., word of mouth, friends, postgraduate students who keep attending schools during the lockdown).

\section{Assessments:}

1- Family violence diagnosing scale: designed by the researchers (2013)

This scale includes 5 types of family violence:

1- Physical violence (25 sentences)

2- Moral violence (verbal / émotionnel / mental) (24 sentences)

3- Social violence (15 sentences)

4- Economic violence (12 sentences) 


\section{5- Threatening with violence sentences)}

The scale was applied on a gender-balanced sample of (400) university, general high school, technical high school and preparatory school students. The scale's validity was tested by interrater validity, factorial validity and construct validity, Cronbach's alpha and testretest were also calculated and all proved the scale's efficiency.

2- Mental health problems scale for child victims of family violence: designed by the researchers

The scale was prepared in two stages:

\section{First stage:}

a- Researchers prepared an open question that aims to pin down the most important mental health problems children in their late childhood suffer from due to experiencing different types of family violence. This includes violence perpetrated by parents, older siblings, stepparents, grandparents and any person living within the family.

"Dear child, you may have experienced different forms of violence, punishment and cruelty. This includes being beaten, insulted, tortured, burned, and deprivation from doing and having things you love. You may have been told that you are a bad person, called with bad nicknames, etc. Being treated this way impacted your mental health or made you hate yourself or others, and made you feel sad, or behave badly to express your anger and refusal." Please mention how you feel and behave at home, with friends and at school as a result to this treatment.

b- 300 male and female students were asked this question in 3 elementary schools in Tanta, Egypt.

c- The researchers identified the behaviors, feelings and actions $100 \%$ of the sample members had in common. That which was not repeated for some of them was excluded, and it was repeated for 88 male students, 92 female students, some of them were randomly excluded, and it was limited to equal responses of 160 male and female students.

d- The researchers categorized the behaviors, feelings and reactions all the final sample members had in common into 8 types (forms) of mental health problems.

\section{Second stage:}

a- The researchers prepared a survey that includes eight sections for the most eight common mental health problems (behavioral, emotional and social problems). Every problem section included 10 sentences that sample members evaluated their occurrence level (High level - average level - low level) $(1-2-3)$.

b- The (160) elementary students sample that addressed these problems were given the survey (to identify the problems' prevalence rate.

c- Frequency value, percentage and arithmetic mean value was calculated for each problem.

d- The problems were arranged based on their prevalence rate in a decreasing order.

\section{Results}

In Frequency value, percentage and arithmetic mean value were calculated for each type of family violence in order to answer the research's first question. Then they were arranged based on their frequency as shown in Table (1).

Table (1) Decreasing order of family violence types prevalence rates

\begin{tabular}{|c|l|l|l|l|l|}
\hline $\mathbf{N}$ & Violence Type & Frequency & $\%$ & $\begin{array}{l}\text { Arithmeti } \\
\text { c Mean } \\
\text { Value }\end{array}$ & $\begin{array}{l}\text { Ran } \\
\mathbf{k}\end{array}$ \\
\hline 1 & Physical & 18 & $11 \%$ & 2.19 & $(5)$ \\
\hline 2 & Moral & 22 & $22 \%$ & 2.64 & $(2)$ \\
\hline 3 & Social & 21 & $14 \%$ & 2.58 & $(3)$ \\
\hline 4 & Economical & 19 & $13 \%$ & 2.22 & $(4)$ \\
\hline 5 & $\begin{array}{l}\text { Threat with } \\
\text { violence }\end{array}$ & 26 & $12 \%$ & 3.34 & $(1)$ \\
\hline
\end{tabular}


The Table(1) shows increase in the high frequency and percentages levels for all family violence types (compared to the average and low levels), as well as the result of each sample member. The frequency and percentage values for the 5 family violence types were decreasingly ordered as follows: threat with violence, moral violence, social violence, economical violence and lastly physical violence.

\section{The Second Question's Results:}

Child victims of violence responses to the researchers' open question indicate many emotional and behavioral problems that occurred due to family violence. Only problems that recurred in all sample members were considered, the rest of problems were excluded. The designed scale put 8 problems into consideration in order to measure the level of this problem (high - average - low). Each problem section in the survey included 10 sentences ( 80 sentences in total). The frequency values, percentages and arithmetic mean values of each question were calculated, then the problems' prevalence rates and high level were concluded (compared to the average and low levels). The result was ordered as follows: lying, destructivity, impulsivity, aggressiveness, fear, night terror attacks, self-harm and finally selfhate as shown in Table (2).

Table (2) Decreasing order of prevalence rates of types of mental health problems types

\begin{tabular}{|l|l|l|l|l|l|}
\hline $\mathrm{N}$ & Problem Type & Frequency & $\%$ & $\begin{array}{l}\text { Arithmetic } \\
\text { Mean Value }\end{array}$ & Ranks \\
\hline 1 & Aggressiveness & 19 & $12 \%$ & 2.18 & $(4)$ \\
\hline 2 & Impulsivity & 21 & $13 \%$ & 2.81 & $(3)$ \\
\hline 3 & Lying & 25 & $16 \%$ & 2.94 & $(1)$ \\
\hline 4 & Destructivity & 22 & $14 \%$ & 2.89 & $(2)$ \\
\hline 5 & Self-harm & 15 & $9 \%$ & 2.15 & $(7)$ \\
\hline 6 & Self-hate & 10 & $6 \%$ & 2.13 & $(8)$ \\
\hline 7 & Sleep terror & 16 & $10 \%$ & 2.16 & $(6)$ \\
\hline 8 & Fear & 18 & $11 \%$ & 2.17 & $(5)$ \\
\hline
\end{tabular}

\section{The Third Question's Result:}

The researchers divided the sample into two categories: family violence high rate and low rate. One-way analysis of variance was applied on the mental health problems in two groups. A group of (80) students with high family violence rate (arithmetic mean $=48.22$ ), and a group of (80) students with low family violence rate (arithmetic mean= 35.76). The result outlined the negative impact of family violence on the children's mental health problems' rate, as it was $(40.11, \mathrm{p} \leq 0.05)$.

\section{Conclusions}

The three questions' results address the five family violence types danger. Family violence resulted 8 different types of mental health problems, and emotional and behavioral disorders. This research conforms the results of many previous researches. One example of these researches is Habola's study (2010), which outlined children's suffer from many mental health problems -including the problems discussed in this research-. This research also conforms the results of the several studies (Lee, 2019; Malti, 2020; Johnson, 1997; Moon, Kim, Seay, Small, \& Kim (2016; Hboula, 2010)

They all address many elementary school students suffer from behavioral and emotional problems, and the relationship between these problems and their family atmosphere Hildebrand et al., 2019. As well as the relationship between harsh parenting and the increase of children's behavioral problems, like aggressiveness, lying, stubbornness, etc.

\section{Recommendations}

The results of the research highlight the danger of using violence against children, and the importance of organizing seminars and advisory sessions to parents to raise awareness about violence's negative present and future impacts on children. The researchers also recommend conducting other studies on the impact of violence on other mental health problems and how they should be treatment. Workshops to mentors and therapists must be organized to educate them about how to treat child victims of family and school violence's problems. Responsible parties on child protection must advocate for criminalizing such actions and to impose effective punishments. 
As physicians, medical care experts, teachers, general wellbeing laborers, and managers, we should remain definitely mindful of the medical services, financial, furthermore, political parts of our individual surroundings. We should stay watchful concerning openings that may emerge wherein we can utilize our impact to forestall and alleviate the impacts of problematic and brutal conditions and occasions. Our cooperation in the public talk with respect to brutality during this pandemic is of fundamental significance.

\section{References}

[1] Ab Hamza, E., Elsantil, Y. G., Moustafa, A. A., \& Abdelhadi, M. (2019). Theprevalence of PTSD and depression among Gaza children. Humanities \& Social Sciences Reviews, 7(6), 464 - 469. doi: https://doi.org/10.18510/hssr.2019.7671

[2] Boddy, J., Young, A. \& O'Leary, P. (2020). Cabin fever: Australia must prepare for the social and psychological impacts of a coronavirus lockdown. The Conversation. Retrieved on 15 April, 2020 from: https://theconversation. com/cabi n-fev erau stralia-mu st-prepare-for- the-social-andpsychological-impacts-ofa-coronaviruslockdown-133353

[3] Bradbury-Jones, C. \& Isham, L. (2020). The pandemic paradox: the consequences of COVID-19 on domestic violence. Journal of Clinical Nursing, https://doi.org/10.1111/jocn.15296

[4] Campbell, A. M. (2020). An Increasing Risk of Family Violence during the Covid19 Pandemic: Strengthening Community Collaborations to Save Lives. Forensic Science International: Reports, 100089.

[5] Enarson, E. (1999). Violence against women in disasters: a study of domestic violence programs in the United States and Canada. Violence Against Women, 5 (7) (742-768).

[6] Hboula, Sherine Ali (2010). A comparative study of a premature child at the primary stage, MA, College of Education. Tanta University.

[7] Hildebrand, N. A., Celeri, E., Morcillo, A. M., \& Zanolli, M. L. (2019). Resilience and mental health problems in children and adolescents who have been victims of violence. Revista de saude publica, 53, 17. https://doi.org/10.11606/S15188787.2019053000391

[8]

[9] Johnson C. (1997). Domestic violence: the cost to society, the challenge to development. Gender action: a newsletter of the USAID Office of Women in Development, 1(4), 2-3.

[10] Kelly, J. \& Morgan, T. (2020). Coronavirus: Domestic abuse calls up 25\% since lockdown, charity says. BBC News. Retrieved on 12th April, 2020 from: https://www.bbc.com/news/uk-52157620

[11] Knowels, M. (2020). Coronavirus lockdown risks murder frenzy - PM sent warning on domestic abuse. The Express. Retrieved on 7th April, 2020 from: https://www.express.co.uk/news/uk/126591 2/coronavirus-lockdownmurder-warningdomestic-abuse-boris-johnson

[12] Lee, B. X. (2019). Violence: An Interdisciplinary Approach to Causes, Consequences, and Cures. Hoboken, NJ: Wiley-Blackwell.

[13] Malti, T. (2020). Children and Violence: Nurturing Social-Emotional Development to Promote Mental Health. Social Policy Report, 33(2), 1-27.

[14] Moon, S. S., Kim, H., Seay, K., Small, E., \& Kim, Y. K. (2016). Ecological Factors of Being Bullied Among Adolescents: A Classification and Regression Tree Approach. Child indicators research, 9(3), 743-756. https://doi.org/10.1007/s12187015-9343-

[15] Peterman, A., Potts, A., O’Donnell, M.et al. (2020).Pandemics and Violence Against Women and Children. Center for Global Development Working Paper, 528.

[16] Posavac, H. D., Sheridan, S. M., \& Posavac, S. S. (1999). A cueing procedure to control impulsivity in children with attention deficit hyperactivity disorder. Behavior modification, 23(2), 234-253. https://doi.org/10.1177/0145445599232003 
[17] Reuters News Agency (2020). As domestic abuse rises in lockdown, France to fund hotel rooms. Aljazeera.Retrievedon7th April, 2020 from: ttps://www.aljazeera.com/ news/2020/03/domestic-abuse-riseslockdown-france-fund-hotel-rooms 200331074110199.html

[18] Shokair, Z. M. (1999). Childhood Fears Scale, Cairo, Anglo-Egyptian.

[19] Shokair, Z., M. (2016). A diagnostic battery of self-hatred and the other and their drivers in the Arab environment. Cairo, Anglo-Egyptian.

[20] Shokair, Z., M. (2006). Child Self-Harming Behavior Diagnostic Scale. Cairo, AngloEgyptian.

[21] Searight, H., Russell (2000) . Adult ADHD Evaluation \& Treatment in family , Medicine American family physician, Vol( 9 ), 135-143.

[22] Shokir, Z. M. (2006). Child Self-Harming Behavior Diagnostic Scale. Cairo, AngloEgyptian.

[23] van Gelder, N., Peterman, A., Potts, A., O'Donnell, M., Thompson, K., Shah, N. \& Oertelt-Prigione, S. (2020). COVID-19: Reducing the risk of infection might increase the risk of intimate partner violence. E Clinical Medicine, Retrieved on 19th April, 2020 from doi: 10.1016/j.eclinm.2020.100348

[24] Wagers, S. (2020). Domestic violence growing in wake of coronavirus outbreak. The Conversation. Retrieved on $10^{\text {th }}$ April, 2020 from: https://theconversation.com/domesticviolence-growing-in-wake-ofcoronavirus-outbreak-135598

[25] World Health Organization. (2020). COVID-19 and violence against women: what the health sector/system can do, 7April 2020 (No. WHO/SRH/20.04). World Health Organization. Retrieved on 10th April, 2020 from https://www.int/reproductivehealth/publicati ons/vaw-covid-19/en 